Relmecs, junio 2017, vol. 7, no. 1, e020, ISSN 1853-7863

Universidad Nacional de La Plata. Facultad de Humanidades y Ciencias de la Educación. Centro Interdisciplinario de Metodología de las Ciencias Sociales.

Red Latinoamericana de Metodología de las Ciencias Sociales

\title{
¿Cómo escribe el etnógrafo?. Una mirada hacia la metodología de Bourgois desde la idea de autoridad etnográfica
}

\author{
¿As the ethnographer writes?. A look towards Bourgois's \\ methodology from the idea of ethnographic authority
}

\section{Cristian Andrés Furfaro *}

* Instituto de de Cultura Jurídica-Facultad de Ciencias Jurídicas y Sociales Universidad Nacional de La Plata, CONICET, Argentina | cfurfaro@hotmail.com

\section{PALABRAS CLAVE RESUMEN}

Philippe Bourgois

Perspectiva metodológica

Autoridad etnográfica

Antropología

Relatos

\section{KEYWORDS}

Philippe Bourgois

Methodological perspective

Ethnographic authority

Anthropology

Stories
El objetivo del presente artículo es analizar la propuesta metodológica que Philippe Bourgois desarrolla en su obra En busca de respeto. Vendiendo crack en Harlem. Para ello, revisaremos la forma en que construye sus categorías teóricas y la estructura del libro, a partir de las observaciones realizadas y de las experiencias y opiniones de los habitantes de East Harlem. En este recorrido, repasaremos las perspectivas teóricas que el autor pone en juego, como así también los elementos que utiliza en la construcción de los relatos. Finalmente, reflexionaremos sobre la idea de autoridad etnográfica presente en el trabajo del antropólogo norteamericano. 


\section{Objetivo del artículo y camino a recorrer}

El objetivo del presente trabajo es analizar la propuesta metodológica que Philippe Bourgois desarrolla en su obra En busca de respeto. Vendiendo crack en Harlem. Para ello, reflexionaremos sobre la forma en que el autor, a partir de las observaciones realizadas y de las experiencias y opiniones de los habitantes de East Harlem, construye sus categorías teóricas y la propia estructura del libro.

En la primera parte de este recorrido repasaremos las perspectivas teóricas que el autor considera necesarias para una visión más compleja de las realidades de los sujetos observados. Asimismo, abordaremos brevemente las consideraciones que realiza Bourgois sobre la tensión entre las cuestiones estructurales y las decisiones individuales de los sujetos.

En la segunda parte examinaremos la forma en que construye los relatos, las herramientas que utiliza para su construcción, las decisiones de edición, el lugar que ocupan los protagonistas en estas decisiones, y las explicaciones del etnógrafo sobre lo que se incluye y lo que no se incluye.

En la última parte nos aproximaremos al lugar que Bourgois otorga a los lectores en la interpretación y construcción del relato y de sus sentidos. Finalmente, reflexionaremos sobre la idea de autoridad etnográfica y la presencia de esta idea en el trabajo de Bourgois.

\section{En busca de respeto: cuestiones introductorias.}

Philippe Bourgois se establece en East Harlem a mediados de los 80 -más precisamente en la primavera de 1985- con el objetivo de "escribir un libro sobre la experiencia de la pobreza y la marginación étnica en el corazón de una de las ciudades más caras del mundo” (Bourgois, 2010, p. 31).

Inicialmente, le interesaba indagar acerca del mundo de la economía informal en la cultura callejera. Su propósito era estudiar los métodos alternativos de generación de ingresos como la reparación de autos, el cuidado de niños, las apuestas y el tráfico de drogas. Sin embargo, la vida en East Harlem le mostró que la economía informal giraba principalmente en torno a una sola actividad: la venta de drogas, y más precisamente, la venta de crack. Este "descubrimiento" lo llevó a focalizar su investigación en la venta de crack en El Barrio ${ }^{1}$. "Al concluir mi primer año (...) la mayoría de mis amigos, vecinos y conocidos habían sido absorbidos por el ciclón multimillonario del crack: lo vendían, lo fumaban, se desesperaban por él” (Bourgois, 2010, p. 31).

La problemática de la economía informal, y más aún la venta de drogas, lo colocan ante un problema ético y metodológico: la necesidad de acercarse a los habitantes de El Barrio para establecer los lazos de confianza que le permitan hacer preguntas incisivas con respecto a temas personales, y lograr respuestas serias y reflexivas.

En este recorrido, el autor narra con detalle el proceso de construcción de la realidad y los dilemas teóricos, metodológicos y éticos que enfrentó, lo que nos lleva a preguntarnos: ¿Cómo escribe el etnógrafo? ¿A qué dilemas se enfrenta? ¿Cómo los resuelve?

\section{Supuestos teórico-metodológicos de partida}

Philippe Bourgois intenta comprender la experiencia de la pobreza y la marginación social desde la perspectiva de la economía política utilizando para ello el marco analítico de la teoría de la producción cultural y algunos principios del feminismo. Reconoce el papel activo de la cultura y la autonomía de los sujetos para la conquista de la dignidad desde la resistencia forjada en la cultura callejera. Al mismo tiempo, destaca el rol fundamental que poseen las relaciones entre los sexos y la esfera doméstica en la configuración 
de la economía informal.

Desde ese posicionamiento, el autor construye una concepción crítica de la inner city $\underline{2}$, desde la cual subraya permanentemente la relación entre las restricciones estructurales y las acciones individuales de los sujetos. A partir de la contemplación de esa relación entre lo estructural y lo individual -e intentando matizar las interpretaciones individualistas o estructuralistas extremas- organiza los temas del libro y presenta las conversaciones con los habitantes de El Barrio.

Lo que en realidad encara el etnógrafo (...) es una multiplicidad de estructuras conceptuales complejas, muchas de las cuales están superpuestas o entrelazadas entre sí, estructuras que son al mismo tiempo extrañas, irregulares, no explícitas, y a las cuales el etnógrafo debe ingeniarse de alguna manera, para captarlas primero y explicarlas después (Geertz, 1987, p. 24).

Bourgois manifiesta que "venir de afuera" lo podía conducir a observar la realidad desde las categorías dominantes de clase, etniay sexo. Se enfrentaba a la dificultad de observar las experiencias de injusticia y opresión, con el riesgo de no tomar dimensión de la autenticidad de estas experiencias. Al mismo tiempo, propone el relato de todas las experiencias vividas en El Barrio, para evitar que la invisibilización de las experiencias "no deseadas", produzca una idea romántica de la vida de los traficantes y de la cultura callejera. Sostiene que los análisis desprovistos de mirada crítica -que "desinfectan” a los marginados para que no resulten desagradables- refuerzan los estereotipos, y se alinean bajo el credo antropológico del relativismo cultural según el cual las culturas no son buenas o malas, sino que simplemente poseen una lógica interna.

Para Bourgois el límite es el sufrimiento humano, pero se siente obligado a exponer sin censura las experiencias vividas. Considera necesario evitar el ocultamiento deliberado de los hechos despojándose del temor a que una imagen desfavorable de los pobres se perciba como injusta, en tanto lo haría cómplice de la opresión. "Cuando un antropólogo niega, porque implica una posición privilegiada (...) colabora con las relaciones de poder y el silencio que permiten que la destrucción se perpetúe” (Scheper-Hughes, 1992, p. 172 en Bourgois, 2010, p. 375).

El análisis de la experiencia individual de la opresión social estructural se construye como una forma superadora de concebir una relación que en los Estados Unidos tiene pocos matices. En la sociedad norteamericana, el individuo es considerado como el único culpable de los males que sufre, dado que mantiene plena vigencia la noción de responsabilidad personal, herencia de la ética protestante. De hecho, el propio Bourgois reconoce que durante sus observaciones y conversaciones le fue difícil percibir las relaciones de poder que configuraban el enjambre de relaciones humanas y sintió en muchas ocasiones ira hacia las víctimas y los victimarios y, luego sí, hacia la sociedad.

La observación e interpretación de la realidad en la inner city hacía necesario considerar el modo en que la historia, la cultura y las estructuras económico-políticas colonialistas restringen la vida de los individuos. Estas restricciones tienen como consecuencia la explotación de clases, la discriminación étnica y la opresión machista, lo que hace indispensable interpretar las sutilezas del significado cultural en su debido contexto.

El análisis político y económico fue "compensado" con la metodología etnográfica, que tiene entre sus principales características permitir "el surgimiento de los «peones» de las fuerzas estructurales” (Bourgois, 2010, p. 47). El autor nos recuerda que las prácticas culturales antagónicas de los individuos "dan forma a la opresión que las fuerzas más grandes le imponen” (Bourgois, 2010, p. 47). La metodología etnográfica debe plantearse la necesidad de comprender los mecanismos y las experiencias de esa opresión. 


\section{Decidir, hacer, justificar}

Bourgois consideró necesario afrontar las contradicciones inherentes a la representación de la marginación social en Estados Unidos mediante la exposición de los acontecimientos sin censura, tal como los experimentó o se los relataron quienes participaron en ellos. Manifiesta explícitamente su decisión de evitar las categorías apriorísticas, con la intención de no reforzar los estereotipos sobre la pobreza que existen en la cultura norteamericana.

Las técnicas etnográficas de la observación participante le permitieron documentar la vida de los individuos marginados, a partir del establecimiento de lazos de confianza. Para lograr estos lazos vivió casi cuatro años en East Harlem y estableció vínculos de larga duración con las personas, se involucró en forma íntima y construyó con ellas un mundo significativo común que le permitía distinguir "los guiños de los tics y los guiños verdaderos de los guiños fingidos” (Geertz, 1987, p. 29). El trabajo de campo le brindó una sensitividad extrema, tanto en la experimentación intelectual y corporal de las experiencias como frente a las problemáticas ineludibles que le planteaban el aprendizaje del lenguaje y la traducción de sensaciones corporales indescriptibles en los términos que la academia acostumbra utilizar.

La observación participante permite al investigador un discernimiento inigualable a nivel metodológico, pero está plagada de tensiones analíticas fundamentales. La injerencia personal requerida incita normalmente a los etnógrafos a omitir el registro de las dinámicas negativas para establecer lazos de empatía con las personas, lo que puede conducir a formas de autocensura que afectan las cuestiones y entornos examinados. $\mathrm{Al}$ mismo tiempo, el consentimiento es más fácil de obtener si los temas abordados son inofensivos. Pese a ello, la etnografía conserva un estatus ejemplar como medio para producir conocimiento a partir de un compromiso intenso e intersubjetivo (Clifford, 2001, p. 41-42).

Bourgois documentó las conversaciones e historias personales a través de un grabador involucrándose con los sujetos, pero intentaba abordar incisivamente las problemáticas. Amaneció en las calles, visitó a las familias, participó en reuniones íntimas, entrevistó y entabló amistad con los vecinos, entrevistó a políticos locales y asistió a reuniones comunales. Pese a ello, consideró que su involucramiento con los vecinos no era suficiente para obviar la influencia que su procedencia del afuera podía tener. Consideró necesario usar la autorreflexión para no olvidar el lugar que poseía en ese espacio y tiempo, y la influencia que ejercía sobre el entorno observado. Esa autorreflexión guio las tareas de edición y contextualización de las conversaciones, y le permitió establecer la estructura del libro. Si bien son los actores quienes otorgan sentido a las acciones, es el observador quien debe construir ese significado en su relación con los signos, el contexto y la situación, reponiendo -en palabras de Barth- los usos sociales situados, su uso en la práctica, sin perder de vista la tríada que contexto, praxis e intención comunicativa conforman.

La edición de los relatos orales planteó a Bourgois una gran dificultad por los obstáculos que presentaba el idioma callejero, con la imposibilidad de transmitir por escrito la dimensión teatral del habla coloquial, o no poder reflejar las entonaciones y expresiones faciales. En el intento de darle a las conversaciones el efecto coherente y poético que tenían en su narración original, el autor eliminó redundancias, frases superfluas, pensamientos incompletos y pasajes enteros. En algunas ocasiones, con la idea de clarificar el sentido, añadió observaciones, comentarios, palabras, verbos y sujetos que le permitieran formar oraciones a partir de fragmentos -uniendo conversaciones sobre el mismo tema para que aparecieran en un solo diálogo- aunque hayan estado separadas por meses o años. En rarísimos casos incorporó a varias personas en un solo personaje. En estos casos, elaboró un corpus textual separado de sus ocasiones discursivas de producción. "Como los autores y actores específicos han sido separados de sus producciones, se tiene que inventar un «autor» generalizado para dar cuenta del mundo o del contexto dentro del cual se han reubicado funcionalmente los textos” (Clifford, 2001, p. 59). 
El respeto al mensaje de los portorriqueños que participaban de la cultura callejera de El Barrio hizo necesario mantener la gramática, el vocabulario expresivo y las formas transcriptas del español que componen su lenguaje. En la nota sobre la traducción, Fernando Montero Castrillo destaca, como una de las decisiones fundamentales que orientaron la traducción de los diálogos, "evitar el español estándar y aprovechar la lengua coloquial de una población específica” con el fin de recrear la naturaleza viva de lo hablado. Se adoptó el habla popular puertorriqueña como instrumento de trabajo con el objetivo "de transmitir la especificidad puertorriqueña y neoyorquina del texto". Se hizo hincapié en "los tonos, los modismos y, en especial, la sintaxis de las clases populares puertorriqueñas” (Bourgois, 2010, pp. 13-14).

La participación de los protagonistas en la construcción de los relatos es otro punto de importancia en la etnografía sobre East Harlem. Bourgois destaca en la sección “Agradecimientos” la participación central de Primo, tanto como guía en el trabajo de campo, como en los comentarios y correcciones que hizo a las múltiples versiones del manuscrito. Menciona asimismo, la importante participación de César -que analizó y criticó los primeros borradores-, Candy y María. Se pone de manifiesto la revisión que hicieron los propios actores de la interpretación del etnógrafo. El autor hace explícita la importancia que ha tenido la colaboración de los protagonistas, que han sido al mismo tiempo sujetos observados, informantes y comentaristas de los relatos sobre sus vidas. Sin embargo, Bourgois destaca que es el autor quien finalmente tiene la última palabra respecto a qué palabras van a transmitirse y cómo van a transmitirse. Siempre es el autor quien en última instancia decide lo que se incluye y lo que no ${ }^{\underline{3}}$. "Los problemas de selección, edición y censura tienen inmensas ramificaciones políticas, éticas y personales que los etnógrafos deben afrontar continuamente sin que jamás puedan confiar en su plena resolución.” (Bourgois, 2010, p. 375).

\section{El etnógrafo y los lectores}

En busca de respeto se construye como una etnografía en la cual se manifiesta una preocupación por el lector. El autor intenta brindar al lector una imagen compleja de la realidad de El Barrio compuesta por diversos aspectos, elementos y sujetos. Decidir como leer esta etnografía, supone que el lector debe elegir a cuales de los aspectos, elementos y sujetos presentes dará preeminencia en la lectura de los relatos.

El libro comienza con notas, agradecimientos y prefacios que van contextualizando las condiciones en que se inicia y desarrolla el trabajo de Bourgois para luego sumergirse en temáticas como el apartheid, la droga, la economía ilegal, el rol de los sexos, la familia y el poder. En este trayecto el autor habla con su voz y con las voces de otros transcribiendo notas de campo, observaciones, diálogos y expresiones, incluyendo estadísticas y cartas, haciendo interpretaciones, consultando sensaciones y sentimientos en los protagonistas. La diversidad de elementos presentados permite observar distintas claves de lectura, las cuales podrían oscilar entre lecturas abstractas sobre la construcción de las categorías teórico-metodológicas y lecturas preocupadas por las experiencias concretas de sufrimiento. No debemos perder de vista que la complejidad de la problemática hace necesarias esas múltiples claves de lectura.

El protagonismo del lector ocupa un espacio central en los debates políticos y epistemológicos sobre la escritura y la representación de los “otros”. Si bien es el autor quien decide qué se incluye en una obra, es el lector quien brinda significado a la lectura, de acuerdo al contexto espacial, temporal y personal en que le ha tocado leer esa obra, y a las búsquedas en las cuales se halla inmerso. Los trabajos de Michel De Certeau y Carlo Guinzburg han sido fundamentales para el desarrollo de la sociología de la lectura. Sus ideas sobre la lectura como práctica productiva -en De Certeau-, o la lectura como conector de la cosmogonía y la cadena de libros -en Guinzburg- han permitido debatir si la clave de lectura es un elemento aún más importante que el propio texto y que el sentido que el autor le ha intentado imprimir.

La estructura del libro, las notas, los agradecimientos, los prefacios y epílogos cobran una dimensión 
fundamental en la contextualización espacio-temporal de la obra e ilustran al lector con las imágenes de lo sucedido antes, durante y después de los casi cuatro años que Bourgois vivió en El Barrio. Esta diversidad de elementos destinados a nosotros, los lectores, pone en juego diversas claves de lectura, que pueden ser distintas o no, a la clave en la cual el autor redactó el libro, y que hasta pueden contradecirla, configurando una práctica, que no puede ser otra cosa que una práctica productiva.

Escribir es producir el texto; leer es recibirlo del prójimo sin marcar su sitio, sin rehacerlo (...) Lo que debe cuestionarse no es, desgraciadamente, esta división del trabajo (sólo resulta demasiado real), sino la asimilación de la lectura a la pasividad. En efecto, leer es peregrinar en un sistema impuesto (el del texto, análogo al orden construido de una ciudad o de un supermercado). Análisis recientes muestran que «toda lectura modifica su objeto», que (Borges ya lo decía) «una literatura difiere de otra menos por el texto que por la forma en que se le lee», y que finalmente un sistema de signos verbales o icónicos es una reserva de formas que esperan sus sentidos del lector. Si entonces «el libro es un efecto (una construcción) del lector», se debe considerar la operación de este último como una especie de lectio, producci ón propia del «lector». Este último no pretende ni el sitio del autor ni un sitio de autor; inventa en los textos algo distinto de lo que era su «intención». Los separa de su origen (perdido o accesorio). Combina sus fragmentos y crea algo que desconoce en el espacio que organiza su capacidad de permitir una pluralidad indefinida de significaciones. (De Certeau, 2000, pp. 181-182).

\section{La autoridad etnográfica. Experiencia e Interpretación en East Harlem}

La formación y quiebra de la autoridad etnográfica ha sido reconstruida por James Clifford en su texto “Sobre la autoridad etnográfica” (2001). En ese artículo el autor hace un repaso sobre los estándares que los modos experiencial, interpretativo, dialógico y polifónico fueron estableciendo, y destaca los autores y las obras centrales de cada uno de ellos ${ }^{4}$. De acuerdo con esa caracterización, individualizaremos algunos aspectos de esos tipos de autoridad etnográfica que observamos en el libro de Bourgois, con la intención de contribuir al debate sobre la etnografía, la escritura etnográfica y los modos de autoridad etnográfica.

En busca de respeto destaca en todo momento la instancia experiencial del etnógrafo $\underline{5}$. El "yo estuve allí" construido amalgama hábilmente la experiencia personal singular del autor y su experiencia como observador participante. Bourgois explicita las dificultades para convivir entre esas dos "experiencias", las dificultades para separar a la "persona" del "científico", lo que "siente” la persona y lo que "piensa" el científico.

En mis años en East Harlem, sumido como estaba en lo que parecía un torbellino de sufrimiento, era difícil percibir las relaciones de poder que configuraban el enjambre de interacciones humanas que sucedían a mi alrededor. Inmerso en el calor de la vida en El Barrio, sentía una confusa ira hacia las víctimas, los victimarios y la rica sociedad industrializada que logra engendrar tal nivel de sufrimiento (Bourgois, 2010, p. 47).

La idea de la familiaridad con los protagonistas y de la progresiva construcción del rapport poseen una presencia muy fuerte a lo largo de la obra: "Quiero empezar agradeciendo a todos mis amigos y vecinos de El Barrio por permitirme entrar en sus vidas” (Bourgois, 2010, p. 15). El autor comienza destacando los vínculos establecidos con los protagonistas para narrar progresivamente -con el transcurso de la escritura, y la lectura- el proceso de integración a la vida cotidiana de los hombres y las mujeres que lo protagonizaron, cómo vivió y habló como ellos, cómo terminó siendo su vecino y amigo.

“Felipe, nos encanta oírte hablar. Suenas igualito a un comercial de la tele” le dice una niña de ocho años al 
iniciar el capítulo 1. Con esta cita, el etnógrafo ilustra un período inicial en el cual aún es un "otro”, aún es ajeno, en el cual su modo de hablar es extraño, en el que los protagonistas no se han acostumbrado a él. La narración sobre su falta de respeto a Ray -que atraviesa el capítulo 1 "Etnia y clase: el apartheid estadounidense"- da cuenta de su ignorancia inicial, su estatus infantil en la cultura observada. A partir de allí construye un relato que, al combinar la narración sobre su vida y sobre el trabajo de campo, nos ilustrará el modo en que obtiene el estatus pleno de observador participante, de vecino y de amigo. El relato de anécdotas atestigua estratégicamente su vinculación y familiaridad con El Barrio, funcionando y funciona como una presunción de conectividad.

Hacia el final del libro, el autor reafirma la familiaridad e involucramiento con los protagonistas. Allí, nos relata cómo continuaron las historias de los protagonistas del libro, nos cuenta qué sucedió con Esperanza, Luis y Candy, pero sobre todo con Primo. En busca de respeto finaliza con una transcripción del último intercambio de mails entre Philippe y Primo. Este involucramiento con los protagonistas marca una diferencia sustancial con los cánones de la investigación positivista, en la cual el científico estudiaba los “objetos" pero no se involucraba con ellos, mantenía la distancia. Bourgois destaca la necesidad de ese involucramiento: "Por lo general, los etnógrafos viven en las comunidades que estudian, y cultivan vínculos estrechos de larga duración con las personas que describen. Para reunir 'datos precisos', los etnógrafos violan los cánones de la investigación positivista. Nos involucramos de manera íntima con las personas que estudiamos” (Bourgois, 2010, p. 43).

La experiencia personal del etnógrafo durante el acceso al campo y las vivencias de los protagonistas ilustran al apartheid como temática "elegida" para el primer capítulo. El autor no elabora una construcción teórica abstracta para darnos a conocer su concepción del apartheid, sino que a partir de las situaciones y diálogos presentados pretende ilustrarnos acerca del vínculo entre las dificultades de El Barrio y el apartheid reinante. La Introducción es uno de pocos espacios donde el autor explicita algunas de las perspectivas teóricas generales que forman parte de su contexto conceptual.

Utilizo el marco analítico de la teoría de la producción cultural y me apoyo en el feminismo con el propósito de avanzar hacia una comprensión de la experiencia de la pobreza y la marginación social desde la perspectiva de la economía política. Tal comprensión sería inconcebible sin reconocer el papel activo de la cultura y la autonomía de los individuos, así como el rol fundamental de las relaciones entre los sexos y la esfera doméstica (Bourgois, 2010, p. 42).

Sin embargo, esta explicitación sobre las decisiones teóricas -de índole general- solo tiene la intención de mostrar al lector cuál es el sentido de las interpretaciones que realizará el autor sobre los diálogos u observaciones realizadas y el lugar ellas han sido ubicadas. Obviamente, no pretende -como lo hace Edward Evans-Pritchard en Los nuer- mostrar la efectividad de la teoría para abordar la realidad. Bourgois presenta al lector un material para la lectio, un relato en el cual intenta equilibrar las restricciones estructurales y las acciones individuales de los protagonistas. Tampoco pretende -como lo hacia la antropología clásica- llegar a la totalidad a través del estudio de una o más de sus partes, como si las partes fueran analogías de esa totalidad. En busca de respeto se focaliza en el análisis de una actividad económica informal -la venta de crack- y muestra ese mundo. No es una etnografía sobre East Harlem ni sobre los guetos, ni sobre la economía informal, es una etnografía sobre el mundo de la venta de crack en East Harlem.

Hacia la primera mitad del siglo XX se había establecido la autoridad del teórico trabajador de procedencia universitaria que amalgamaba experiencia personal intensa -trabajo de campo intensivo- y análisis científico, el cual utilizaba como método la observación participante. Este canon de autoridad proponía la fusión de teoría general e investigación empírica, y lograba complementar el análisis cultural con la descripción etnográfica. La observación participante se constituye en el primer momento de la dialéctica 
entre experiencia e interpretación.

En busca de respeto prioriza la experiencia de vida y de trabajo del etnógrafo, que se ve fortalecida por el establecimiento de un mundo experiencial compartido. Las citas y diálogos recreados son presentados y ordenados en el marco del contexto conceptual especificado con la finalidad de que el lector pueda entenderlos en la tensión entre restricciones estructurales y acciones individuales. El capítulo 3 -“La administración de una casa de crack: dependencia, disciplina y dignidad”- aborda la tensión entre la venta de crack y la inserción laboral de los protagonistas en la economía convencional; analiza, a través de la observación participante y de la entrevista, la repercusión cotidiana de esta tensión en el Salón de Juegos. Intercala brillantemente los relatos, los contextos donde se desarrollan esos relatos y conversaciones, con algunos datos que, presentados descriptivamente, son fundamentales para construir el mundo de la venta de crack. En este capítulo dialogan las formas experienciales e interpretativas a través de los relatos y las reflexiones del autor, lo que le permite al lector trasladarse desde los comienzos del Salón de Juegos hacia las cuestiones organizacionales y de conflicto laboral que coexisten en el mundo de la venta de crack.

En el desarrollo del libro, el etnógrafo se hace siempre presente, se incluye en los diálogos, nos relata qué hacía mientras los protagonistas hablaban, nos muestra que estaba "allí". Su "presencia” parece contraponerse con la "casi invisibilidad" de la antropología interpretativista clásica. Esta visibilidad, esta presencia del etnógrafo se refuerza al explicitar los procesos creativos que el autor produce para componer En busca de respeto. "La antropología interpretativa desmitifica gran parte de lo que anteriormente permanecía no cuestionado en la construcción de las narrativas, los tipos, las observaciones y las descripciones etnográficas. Contribuye a una visibilidad creciente de los procesos creativos..." (Clifford, 2001, p. 57), lo que constituye el segundo momento de la dialéctica entre experiencia e interpretación. Bourgois, como etnógrafo siempre visible, siempre presente, explicita los modos en que ha construido y reconstruido los relatos y diálogos.

...frecuentemente eliminé redundancias, frases superfluas, pensamientos incompletos y en ocasiones pasajes enteros, para recuperar el efecto coherente, y a menudo poético, que ese mismo pasaje transmitía en su narración original. De vez en cuando, para clarificar el sentido, añadí palabras e incluso verbos y sujetos para formar oraciones a partir de fragmentos. En ocasiones también uní conversaciones sobre el mismo tema para que aparecieran como un solo diálogo en el texto, aunque las discusiones se hayan efectuado a lo largo de varios meses o años. En pocos y rarísimos casos, a los fines de la brevedad, incorporé a varias personas en un solo personaje (Bourgois, 2010, p. 375).

La textualización geertziana -tomada de Paul Ricouer- se constituye en un prerrequisito de la interpretación: "Es el proceso a través del cual la conducta no escrita, el habla, las creencias, la tradición oral y el ritual son caracterizados como un corpus, como un conjunto potencialmente significativo separado de toda situación discursiva o performativa inmediata” (Clifford, 2001, p. 58). El corpus se relaciona de manera estable con el contexto y permite que se construya la descripción densa etnográfica. En el segundo paso, Ricoeur transforma el discurso en texto, lo vuelve autónomo, separado de elocuciones e intenciones autorales específicas, se inventa un autor generalizado que da cuenta del mundo. El etnógrafo elabora un retrato integrado del mundo en el que se desvanecen los aspectos dialógicos y situacionales de la interpretación.

La lectura de En busca de respeto nos lleva a preguntarnos: ¿Es posible hacer una descripción densa etnográfica sin que tiendan a desvanecerse los aspectos dialógicos y situacionales de la interpretación? ¿Las narraciones sobre el trabajo de campo, las leyendas de rapport y las anécdotas constituyen topoi que fortalecen el modo interpretativo de autoridad etnográfico? O por el contrario, ¿estos topoi abren la puerta a los modos dialógicos y polifónicos? ¿En busca de respeto esboza posibles respuestas para estas preguntas?

El segundo momento de la dialéctica entre experiencia e interpretación es el que abre el juego a la 
“desfamiliarización de la autoridad etnográfica”. La etnografía comienza a concebirse "como una negociación constructiva que involucra por lo menos a dos, y habitualmente a más sujetos”, y se constituyen así los paradigmas discursivos del diálogo y la polifonía como modos emergentes de autoridad etnográfica (Clifford, 2001, p. 61).

\section{Crítica y revisión de la autoridad etnográfica. Dialogismo y polifonía en El Barrio}

La idea de un modelo discursivo de la práctica etnográfica implica dar preponderancia a la intersubjetividad de todo enunciado y su contexto performativo inmediato. Esto significa que el discurso y su significado están ligados a una situación compartida específica, y que es preciso conocer cuáles son las interlocuciones y el contexto en el cual se desarrollan. En busca de respeto está redactado de manera tal que los diálogos y relatos advierten al lector sobre la multiplicidad de hombres y mujeres protagonistas, lo que ellos dicen y hacen, las características del espacio y lo que pasa a su alrededor. En el capítulo 1 -“Etnia y clase: el apartheid estadounidense"-, el autor presenta los personajes en diálogos y relatos, en los que describe sus actitudes, y los lugares donde se dieron esas situaciones y conversaciones. Ello, como marco para entender las dificultades que Bourgois afrontó en sus comienzos y las sospechas que recaían sobre su presencia e intenciones en un espacio al cual no pertenecía. De acuerdo a este modelo discursivo se hace necesario analizar cuáles son los sujetos y las voces que el autor incluye, cómo es el lenguaje de cada uno de ellos y la forma en que se refleja el contexto en el cual se desarrollan los diálogos, relatos y observaciones incluidos.

Las vivencias e interpretaciones del etnógrafo se presentan en todo momento como sujetas al "control” de los protagonistas. La etnografía de Bourgois establece un proceso de diálogo entre el autor y sus interlocutores, en el que -al estilo que Clifford sitúa la idea de Dwyer y Crapanzano- se "negocia” activamente una visión compartida de la realidad. Los diálogos de los primeros capítulos destacan -principalmente- los intercambios entre Philippe, Primo y César. En ellos, los “nativos” interpelan al etnógrafo acerca de su visión de la realidad de El Barrio para que entienda sus puntos de vista y los motivos que fundamentan sus acciones. El texto incluye las discusiones que modificaron la comprensión del autor sobre el contexto y sobre las estrategias de los sujetos. Los diálogos se presentan como instancias ad hoc, en las que los protagonistas “controlan” las interpretaciones del etnógrafo. Esta visión compartida de la realidad se plasma explícitamente y de modo general en los Agradecimientos:

Quiero agradecer sobre todo a quien he llamado Primo en estas páginas. Él siguió de cerca este proyecto de principio a fin, guio gran parte de mi trabajo de campo (...) Los comentarios y correcciones que aportó al leer o escuchar múltiples versiones del manuscrito fueron de gran valor (...) César me ofreció críticas y análisis perspicaces al leer mis primeros borradores. Candy también me apoyó muchísimo durante el trabajo de campo así como en la etapa de redacción. María me brindó apoyo moral e hizo comentarios útiles en la fase final de redacción del texto (Bourgois, 2010, p. 15).

En busca de respeto también contiene otras voces, voces que cobran una importancia fundamental en clave de traductores, intérpretes e informantes, permitiendo volver más "denso" el entramado sociocultural de El Barrio. La vieja idea de "hombres en el terreno" nos permite recuperar el papel de aquellos sujetos que colaboran con el autor para comprender la complejidad de la vida en East Harlem. Philippe Bourgois destaca la tarea del traductor Fernando Montero Castrillo, en tanto sus habilidades lingüísticas fueron necesarias para la correcta transmisión de los tonos, los modismos y la sintaxis de las clases populares puertorriqueñas. Al mismo tiempo, la lectura de las notas nos permite observar el asiduo intercambio que el etnógrafo realizaba con trabajadores de distintos organismos públicos. La colaboración de Frank Vardi, del Departamento de Planificación Urbana de la Ciudad de Nueva York, o de Kevin Kearny, del Instituto Neoyorquino de la 
Vivienda, tanto para la obtención de estadísticas o informes como para su interpretación, le permitieron conocer al autor las múltiples lecturas posibles a que dichos documentos daban lugar. Bourgois explicita la necesidad de contar con traductores, intérpretes e informantes que le permitan comprender la complejidad a la cual se enfrentaba al abordar el mundo de la venta de crack.

Generalmente, observamos la voz del etnógrafo en clave de observador participante, sin embargo, En busca de respeto nos permite individualizar la voz de Philippe Bourgois como padre, esposo y protagonista de la vida en East Harlem . En el capítulo 7 -“Familias y niños que sufren”- podemos observar narraciones sobre la experiencia de vida de la familia del etnógrafo, que se focaliza en el modo en que ésta resulta afectada en sus propias dinámicas.

Como padre de familia, aprendí la lección que deben enfrentar todos los padres y madres trabajadores de El Barrio. Al igual que ellos, yo tenía dos opciones: abandonar el espacio público y encerrar a mi hijo con candado en nuestro pequeño departamento, o afrontar la realidad de que conviviríamos diariamente con las drogas (Bourgois, 2010, p. 277).

James Clifford considera que toda etnografía incluye una diversidad de descripciones, transcripciones e interpretaciones que se deben a una variedad de autores, y se pregunta cómo es posible tornar manifiestas estas presencias. Para responder a ello, recupera el análisis de Mijail Bajtín sobre la novela polifónica, la heteroglosia y el descubrimiento de "un espacio textual donde se pueden acomodar la complejidad discursiva y la interacción dialógica de voces” (Clifford, 2001, p. 67). Y se pregunta en tono dicotómico: el etnógrafo en la tarea de retratar el pensamiento "nativo": ¿utiliza el estilo libre indirecto flaubertiano, suprimiendo la cita directa a favor de un discurso controlado que es siempre más o menos el del autor, o construye esas otras subjetividades a través de una versión menos homogénea, con diferentes voces dickensianas? Bourgois parece darle la razón a Clifford cuando este manifiesta: “Algún uso del estilo indirecto es inevitable, a menos que (...) la etnografía se componga enteramente de citas” (Clifford, 2001, p. 67). La historia de los protagonistas, sus opiniones y actitudes son presentadas en diálogos y relatos, algunas veces como citas y otras como imputaciones del autor.

En busca de respeto es una polifonía con diferentes voces, pero esas voces ni están completamente construidas sobre citas -como los trabajos de Víctor Turner- ni son pulidas en una prosa de informantes intercambiables. Cada protagonista tiene su voz y su opinión sobre cada uno de los temas tratados. Las historias de vida de los capítulos 5 -"La educación criminal”- y 6 -“Redefinición callejera del rol de los sexos”- permiten reconstruir la historia de cada personaje y elaborar un retrato de su voz y sus opiniones identificando las formas de expresión propias de cada protagonista.

La intersubjetividad de los diálogos requiere dar cuenta de la identidad de cada protagonista, de sus voces y lenguajes, y de las intenciones y acentos que posee ese lenguaje. La utilización del léxico puertorriqueño previa construcción de un dialogo con el español estándar- y las descripciones en las que se explicitan las actitudes corporales permiten construir un esbozo de polifonía, en la que cada protagonista tiene una voz, una actitud corporal y formas de expresión diferentes, para lograr que ello se plasme en el texto.

Las palabras de la escritura etnográfica, por lo tanto, no se pueden construir como si fueran monológicas, como afirmaciones autoritarias sobre, o como interpretaciones de una realidad abstracta y textualizada. El lenguaje de la etnografía está afectado por otras subjetividades y por resonancias contextuales específicas, puesto que todo lenguaje, en la concepción de Bajtín, es «una concreta visión heteroglósica del mundo» (Clifford, 2001, p. 62).

Las situaciones compartidas y las resonancias contextuales específicas se reflejan en las construcciones narrativas. En ellas, el escritor intenta reflejar las presencias de los sujetos, sus voces, sus acciones y el 
espacio donde se desarrollaba cada una de las escenas.

Metido de lleno en ese ambiente, pensé que era un buen momento para compartir el pequeño éxito mediático que había logrado esa mañana: una foto mía en la página 4 del New York Post junto al presentador de televisión Phil Donahue (...) Yo esperaba que esto impresionara a Ray (...) La foto en el diario era una manera de legitimar mi presencia. Noté que Ray se contrajo e hizo una cara extraña cuando le pasé el periódico, pero era demasiado tarde para detenerme. Yo ya había gritado: «¡Ey Big Ray, mira mi foto en el periódico!», en voz alta para que todos escucharan. Media docena de voces habían empezado a pedirle que leyera (...) Ray hacía un intento torpe (...) sus admiradores le pidieron con más firmeza que leyera. «iVamos, Ray! ¿Qué pasa?». (...) En una ráfaga de lucidez, por fin reconocí el problema: Ray no sabía leer. Desafortunadamente lo intentó. (...) la herida del fracaso institucional que Ray cargaba desde niño (...) se había abierto repentinamente. «¡Coño, Felipe, me impolta un carajo! Lárguense de aquí. ¡Todos!»Con torpeza, acomodó su cuerpo en su Mercedes (...) y dio vuelta a las esquina (...) sin prestar atención ni a la luz roja ni a los traficantes que se encontraban frente a La Farmacia y que con su semblante de sobrevivientes de Auschwitz esquivaron el Mercedes y siguieron vendiendo cocaína, heroína adulterada, Valium y polvo de ángel (Bourgois, 201, pp. 50-51).

La narrativa detalla las acciones de los protagonistas y de los transeúntes en los contextos en los cuales se desarrolla la observación participante. De esta manera, se intentan recrear los sentidos que las palabras y las acciones de los protagonistas, los interlocutores, poseen en situaciones contextuales específicas, es decir, las resonancias contextuales específicas que afectan el lenguaje de la etnografía. De forma más general, el capítulo 2 -"Una historia de las calles de El Barrio"- construye una historia de East Harlem, de la marginación y de la forma en que la venta de drogas se instituye en la actividad dominante y crea así el contexto general en el cual podrán interpretarse los relatos, diálogos y observaciones incluidos en el libro.

\section{Algunas reflexiones}

La autoridad etnográfica fue objetada por la explosión de la teoría posmodernista en la antropología de los años 80 y 90, con la denuncia de la jerarquía inherente a la política de la representación antropológica. Para Bourgois, la deconstrucción de los adeptos al posmodernismo suele limitarse a una retórica hermética y cerrada sobre la poética de la interacción social, sin un verdadero anclaje en las luchas cotidianas concretas y las experiencias de sufrimiento: "La autorreflexión, reivindicada por los posmodernistas, resultó ser necesaria y útil en mi caso: yo venía de afuera, procedente de las categorías dominantes de clase, etnia y sexo, a intentar estudiar la experiencia de los puertorriqueños pobres en la inner city” (Bourgois, 2010, p. 43). La autorreflexión del etnógrafo debe cumplir un papel central en la antropología contemporánea.

Ahora es más crucial que nunca que los diferentes pueblos formen imágenes complejas y concretas de los demás, y de las relaciones de conocimiento y poder que los conectan. Pero ningún método científico o instancia ética soberanos pueden garantizar la verdad de tales imágenes. Ellas están constituidas -la crítica de los modos coloniales de representación lo ha mostrado suficientemente- en términos de relaciones históricas específicas de dominación y diálogo (Clifford, 2001, p. 41).

El texto de Bourgois constituye un experimento de escritura etnográfica que ejemplifica acabadamente el uso de la noción deleuziana-foucaultiana de la teoría como caja de herramientas. La teoría que se construye es un instrumento, una lógica de la especificidad de las relaciones de poder y de las luchas alrededor de ellas, y la investigación se lleva paso a paso sobre la base de una reflexión -necesariamente histórica- acerca de situaciones determinadas (Clifford, 2001, p. 41). Para Bourgois, el etnógrafo debe hablar abiertamente y enfrentar el dolor aunque hacerlo perturbe e incomode. Debe documentar las estrategias ideadas para eludir 
las estructuras de segregación y marginación con la esperanza de que la antropología pueda ser un foco de resistencia para enfrentar al poder.

...siempre está el peligro de que el análisis cultural, en busca de las tortugas que se encuentran más profundamente situadas, pierda contacto con las duras superficies de la vida, con las realidades políticas y económicas dentro de las cuales los hombres están contenidos siempre, y pierda contacto con las necesidades biológicas y físicas en que se basan esas duras superficies. La única defensa contra este peligro y contra el peligro de convertir así al análisis cultural en una especie de esteticismo sociológico, es realizar el análisis de esas realidades y esas necesidades en primer término. (Geertz, 1987, p. 40).

De allí la necesidad de presentar En busca de respeto como una etnografía cuyo silencio monofónico se quiebra con voces insistentes, heteroglóticas, con el raspar de otras plumas (Clifford, 2001, p. 43), sin olvidar que los personajes del libro 'no son otros exóticos' habitantes de un mundo irracional aparte, sino productos made in USA” (Bourgois, 2010, p. 341).

En busca de respeto debe ser entendido en el marco de la "crisis” o "dispersión” de la autoridad etnográfica. En su obra, Bourgois combina estratégicamente las características clásicas de los modos experiencial e interpretativo de autoridad, e introduce algunos aspectos de la polifonía y el dialogismo, como forma de provocación a las tradiciones antropológicas. Philippe Bourgois vivió cuatro años en East Harlem, desarrollando su etnografía a través de la fusión entre un marco analítico general y la observación participante como método, y practicando la “descripción densa”. Pero también pugnó por asentar en su obra las voces de los protagonistas, transcribiendo las conversaciones, contextualizándolas y obrando como interlocutor. Se ocupó de los contextos de la investigación y de las situaciones de diálogo, para luego componer su obra en un taller de escritura. El resultado de ello, esa visión compartida de la realidad, se abre hacia la autoridad del lector, creando así una etnografía que ningún modo de autoridad etnográfica puede encasillar.

Los diálogos y las polifonías presentados solo constituyen una representación de esos diálogos y de esas voces, y solo sirven para desplazar la autoridad monológica, para comenzar a quebrarla, nunca para eliminarla. Michel De Certeau nos enseñó que entre el escritor y el lector existe una relación desigual, y que es siempre el escritor, quien decide en última instancia qué se incluye y qué no. Sin embargo, es necesario recordar que la etnografía es una actividad plural que se encuentra más allá del control de cualquier individuo. Para James Clifford, la quiebra de la autoridad monológica requiere una etnografía dirigida a diferentes tipos de lectores, requiere una apertura a lecturas no planificadas. "La teoría literaria reciente sugiere que la capacidad de un texto para alcanzar sentido de una manera coherente depende menos de las intenciones buscadas por un autor original que de la actividad creativa de un lector” (Clifford, 2001, p. 73).

Creemos que En busca de respeto constituye una etnografía que se abre a los modos emergentes de autoridad basados en el dialogo y la polifonía, y que provoca en el lector dudas sobre la propia versión del mundo que el autor presenta. En este ejercicio, Bourgois -aun como escritor que elige lo que incluye- dispara al centro del concepto de autoridad etnográfica y "le pasa la pelota” al lector, lo que le otorga a la lectio el poder de un acto creativo. Este acto creativo empodera a cada lectura. Cada acto de lectura tiene el poder tanto de dar “autoridad etnográfica” a una obra, como así también, el de quitarla. Se puede repetir el nombre de la obra, el nombre del escritor y el nombre del lector, pero no se pueden repetir los tiempos y los espacios en los que cada una de esas obras fue escrita y, fundamentalmente, leída.

La etnografía está atrapada ineludiblemente en la red de la escritura, y debe afrontar la dificultad de traducir las experiencias, las interpretaciones, los diálogos y la polifonía a una forma textual. En este punto, no creemos en fórmulas mágicas, pero sí en la habilidad -y en la sinceridad- del autor para expresar sus 
decisiones, fundamentar sus selecciones, y contar detalladamente como obró en la edición de miles de páginas de transcripciones. No pretendemos que nos convenza de lo verdadero de su imagen, sino que tan solo queremos conocer lo que ignoramos, lo que el autor incluyó y lo que no. Bourgois sabe que es parte de una discusión metodológica la forma en que se analiza el relato de los protagonistas, pero también sabe que es parte de una discusión política la forma en que puede ser leída su obra, y es allí que elige devolverle la responsabilidad al lector.

La escritura de la etnografía, una actividad ingobernable y multisubjetiva, alcanza coherencia en actos particulares de lectura. Pero siempre hay una variedad de lecturas posibles (más allá de las apropiaciones meramente individuales), lecturas que están más allá del control de cualquier autoridad singular. Uno se puede acercar a una etnografía clásica buscando simplemente aferrar los significados que el investigador deriva de los hechos culturales representados. $\mathrm{O}$, como he sugerido, uno puede también leer en contra del grano de la voz dominante en el texto, en pos de otras autoridades casi escondidas, reinterpretando las descripciones, los textos y las citas reunidas por el escritor. (Clifford, 2001, p. 73).

En el frontispicio imaginario de En busca de respeto vemos a Felipe, con un grabador en su mano, hablando y tomando cerveza con Primo y César. Los tres están sentados en el capó de un auto, en la puerta del Salón de Juegos, mientras Emiliano, el hijo de Felipe, corre alrededor de ellos. En este frontispicio, no hay un taller de escritura ni una presencia sugerida detrás de las lentes fotográficas; el etnógrafo está ahí, ante nuestros ojos, construyendo una etnografía mientras, simplemente, vive. Y más allá estamos nosotros, los lectores, con un mundo lleno de claves de lectura por explorar.

\section{Notas}

1 En Nueva York, El Barrio se utiliza específicamente para referirse a East Harlem.

$\underline{2}$ "La expresión inner city surgió en los años ochenta en los Estados Unidos como un eufemismo de la palabra «gueto», que sigue utilizándose en la lengua coloquial para referirse a los enclaves urbanos altamente segregados como el Bronx y Harlem. No hay palabra en español que condense los significados culturales, sociales y políticos que ha llegado a poseer esta expresión.” (Bourgois, 2010, p. 31).

$\underline{3}$ "En realidad, decidí excluir varias conversaciones y observaciones que, pensé, proyectarían una imagen exageradamente negativa de los vendedores de crack y sus familias fuera de su debido contexto. La mayor parte de las descripciones que «censuré» tenían que ver con actividades sexuales. En varios casos, sentí que los pasajes eran indudablemente pornográficos” (Bourgois, 2010: 375).

4 En la nota 3, Clifford advierte "No pretendo revisar nuevos estilos de escritura etnográfica que se han originado fuera de Occidente (...) Mi análisis permanece en el interior, pero en los límites experimentales de una ciencia cultural realista elaborada en Occidente” (Clifford, 2001, p. 75).

5 “Me mudé a El Barrio en marzo de 1985 y viví allí con mi familia hasta septiembre de 1990. Por razones económicas tuvimos que pasar varios semestres académicos fuera de Nueva York, de manera que el total de tiempo que estuvimos físicamente en el vecindario fue de tres años y medio, dos de ellos (de 1988 a 1990) ininterrumpidos” (Bourgois, 2010, p. 377).

$\underline{6}$ “... quiero darle las gracias a mi familia. Siempre le estaré agradecido a Charo Chacón Méndez por haber emigrado de Costa Rica directamente a El Barrio, donde nos casamos justo al comienzo de este proyecto de estudio (...) A nuestro hijo Emiliano le encantaba El Barrio. La calle nunca lo amedrentó” (Bourgois, 2010, p. 17). 


\section{Bibliografía}

Alarcón, C.; Bourgois, P. (2010). Narrar el mundo narco: diálogo con Cristian Alarcón y Philippe Bourgois. Salud Colectiva, 6(3), 357-369.

Barth, F. (2000). A análise da cultura nas sociedades complexas. En O Guru, o iniciador e outras variações antropológicas (pp. 107-119). Rio de Janeiro: Contracapa.

Bourgois, P. (2010). En busca de respeto. Vendiendo crack en Harlem. Buenos Aires: Siglo XXI.

Clifford, J. (2001). Sobre la autoridad etnográfica. En Dilemas de la cultura. Antropología, literatura y arte en la perspectiva posmoderna (pp. 39-77). Barcelona: Gedisa.

De Certeau, M. (2000). La invención de lo cotidiano. México: ITESO.

Geertz, C. (1987). Descripción densa: hacia una teoría interpretativa de la cultura. En La Interpretación de las Culturas (pp. 19-40). México: Gedisa.

Ginzburg, C. (1999). El queso y los gusanos. Barcelona: Muchnik Editores/Biblos.

Guber, R. (2011). La etnografía. Método, campo y reflexividad. Bs. As: Siglo XXI Editores. 